\title{
You are my best friend: Commitment and stability in adolescents' same-sex friendships
}

\author{
SUSAN J. T. BRANJE, ${ }^{a}$ TOM FRIJNS, ${ }^{a}$ CATRIN FINKENAUER,${ }^{b}$ RUTGER \\ ENGELS $^{c}{ }^{c}$ AND WIM MEEUS ${ }^{a}$ \\ ${ }^{a}$ Utrecht University, Utrecht, The Netherlands; ${ }^{b}$ Free University of Amsterdam, \\ Amsterdam, The Netherlands; ${ }^{c}$ Radboud University Nijmegen, Nijmegen, \\ The Netherlands
}

\begin{abstract}
A 2-wave longitudinal study among 678 early and 317 middle adolescents investigated the applicability of Rusbult's investment model to adolescent best friendships and tested its usefulness in predicting friendship stability. Results showed that satisfaction, quality of alternatives, and investments predict commitment in friendships, both concurrently and over time. Furthermore, investment model variables predicted friendship stability and, among stable friendships, predicted the tendency to switch best friends. Commitment mediated the effects of satisfaction, investment, and alternatives on tendency to switch. As expected, gender and age differences were found in that alternatives were more important for older adolescents and associations among model variables were stronger for girls. Overall, the investment model proved useful in predicting commitment and stability in adolescents' best friendships.
\end{abstract}

According to Rusbult's investment model of romantic commitment, relationship satisfaction and investments are positively related to relationship commitment, whereas the quality of alternatives to the current romantic partner is negatively related to relationship commitment (Rusbult, 1983; Rusbult, Johnson, \& Morrow, 1986). Commitment is defined as intent to persist in a relationship, including psychological attachment and a long-term orientation toward the partnership (Rusbult, Martz, \& Agnew, 1998). Satisfaction with the relationship concerns the extent to which the benefits of the relationship exceed the costs and the relation-

Susan J. T. Branje, Tom Frijns, and Wim Meeus, Research Centre Adolescent Development, Utrecht University, Utrecht, The Netherlands; Catrin Finkenauer, Department of Social Psychology, Free University of Amsterdam, Amsterdam, The Netherlands; Rutger Engels, Behavioural Science Institute, Radboud University Nijmegen, Nijmegen, The Netherlands.

Correspondence should be addressed to Susan J. T. Branje, Utrecht University, Research Centre Adolescent Development, P. O. Box 80140, 3508TC Utrecht, The Netherlands, e-mail: s.branje@uu.nl. ship meets or exceeds their expectation about the quality of that kind of relationship. Individuals are also more committed if they have made investments in the relationship that may be lost if the relationship ends, and they are more committed if they have poor alternatives to the relationship (see Figure 1). Although the investment model is generalizable to other contexts such as commitment to career (Rusbult \& Farrell, 1983) or sports (e.g., Carpenter \& Coleman, 1998), it is most fruitful in explaining processes in interpersonal relationships, especially in romantic and marital relationships. A recent meta-analysis (Le \& Agnew, 2003) even shows that satisfaction, alternatives, and investments account for nearly two thirds of the variance of commitment, which in turn is a good predictor of relationship breakup. The current study investigates the extent to which the investment model is applicable to adolescents' same-sex best friendships.

The investment model can predict relationship stability. Individuals with higher investments, satisfaction, and commitment and 


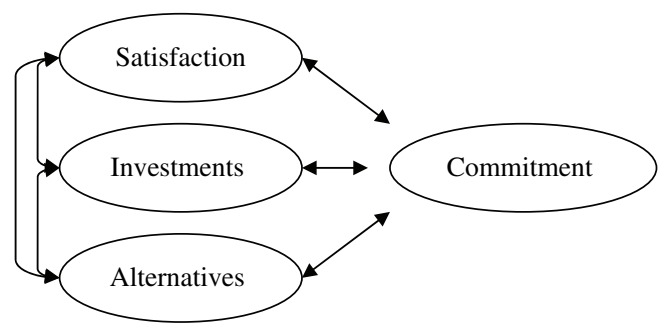

Figure 1. Associations between satisfaction level, investment size, quality of alternatives, and commitment level.

lower quality of alternatives are more likely to continue their relationship (Bui, Peplau, \& Hill, 1996; Floyd \& Wasner, 1994). Commitment is the most powerful predictor of persistence in partner relationships and mediates the effects of satisfaction, alternatives, and investments on persistence and stability. Nonetheless, evidence for the mediating role of commitment is mixed. Bui et al. (1996) found that commitment fully mediated the effect of satisfaction and partly mediated the effect of quality of alternatives on relationship stability but did not find evidence of mediation for investments. Sacher and Fine (1996) did not find mediating effects of commitment on relationship stability among dating couples, although they found direct effects of quality of alternatives and relationship satisfaction. In the current study, we examine relations between investment, satisfaction, quality of alternatives, commitment, and stability in best friendships during adolescence. Additionally, we examine the mediational role of commitment in the predicted links of satisfaction, alternatives, and investments with future commitment and relationship stability.

\section{The investment model in friendships}

Friendships are characterized by voluntariness and by the equality, symmetry, mutual liking, and reciprocity of the dyadic partners (Laursen \& Bukowski, 1997; Oswald, Clark, \& Kelly, 2004). Although they are thus similar to romantic relationships, they differ in an important aspect: Friendships are not as exclusive as romantic relationships. Unlike romantic or marital relationships, individuals can have multiple simultaneous friendships. The quality of alternatives may therefore not be as important in determining commitment and relationship stability in friendships as it is in romantic relationships (e.g., Le \& Agnew, 2003).

A number of studies have applied the investment model to friendships and investigated commitment in friendships (e.g., Lin \& Rusbult, 1995; Rusbult, 1980). Rusbult (1980) found significant relations between all the model variables in the predicted directions in best friendships. Lin and Rusbult (1995) found that satisfaction and quality of alternatives were more weakly related to commitment in cross-sex friendships than in dating relationships. In fact, the link between alternatives and commitment was nonsignificant in crosssex friendships. These authors suggest that this apparent discrepancy with previous findings may be due to quality of alternatives affecting commitment primarily in relationships that are at least somewhat exclusive, as is often the case with dating partners and best friends. In adolescence, one can maintain multiple good friendships at the same time but may choose the better alternative in romantic relationships (Feiring, 1999). Although adolescents often have more than one "best" friend, the best friend relationship implies some exclusivity compared to other friendships, and previous research has shown that this dyadic relationship is much stronger than other types of friendship (i.e., other close friends; Degirmencioglu, Urberg, Tolson, \& Richard, 1998; Newcomb \& Bagwell, 1995). This leads us to suggest that the role of good alternatives in the prediction of commitment and relationship stability in adolescent friendships may be less pronounced than it is in romantic relationships (e.g., Le \& Agnew, 2003).

\section{Predicting stability of adolescents, friendships}

Friendships are more stable in adolescence than in childhood (Berndt \& Hoyle, 1985) and become even more stable during adolescence (Neckerman, 1996). This increase in stability is attributable to adolescents' increased sophistication in coordinating multiple views 
and understanding interpersonal dynamics (Selman, 1981), which aids in forming and maintaining friendships. Even so, fewer than half of adolescents' reciprocal best friendships last longer than 1 year, although the partners may remain close friends (Connolly, Furman, \& Konarski, 2000; Degirmencioglu et al., 1998). Girls are more likely to change friends during the transition to middle-level school than boys are, and they are better at forming new relationships than boys (Hardy, Bukowski, \& Sippola, 2002). In late adolescence, the transition from high school to college brings change for adolescents' best friendships (Oswald \& Clark, 2003). By the end of the first year of college, high school best friendships show a significant increase in quality of alternatives and decreases in satisfaction and commitment, and about half of the best friendships have become close or casual friendships. Surprisingly, but consistent with the greater likelihood for girls to change friends, friendships were less stable when adolescents were highly engaged in this relationship (i.e., highly emotionally involved in the relationship in both positive and negative terms) than when adolescents were disengaged and when they reported less positive aspects of the relationship (Way, Cowal, Gingold, Pahl, \& Bissessar, 2001). Individuals who are more engaged in their friendships may be more likely to change friends when the relationship does not meet their expectations. In line with this evidence, we expect investment-related processes to be associated with friendship stability and expect that satisfaction, investments, alternatives, and commitment will predict friendship stability.

In addition to these general predictions regarding the investment model in adolescents' friendships, we expect that sex differences in friendships affect the role of specific aspects in the investment model. During adolescence, the nature of friendships differs between boys and girls, with girls' friendships being more exclusive and intimate than boys' friendships (Cairns, Leung, Buchanan, \& Cairns, 1995). Girls generally have smaller friendship networks than boys and different styles of dominance and influence, activities, linguistic styles, and play styles (Graham, Cohen, Zbikowski, \& Secrist, 1998). Also, girls attribute higher quality to their friendships than boys do (Brendgen, Markiewicz, Doyle, \& Bukowski, 2001). In adulthood, females tend to be more interpersonally oriented (Worrell, 1988) and to work harder at maintaining their relationships than males (Acitelli, 1992; Kirkpatrick \& Davis, 1994; Sprecher, 1994), and the investment model predicts relationship stability better for females than for males (Sacher \& Fine, 1996). Because friendships of girls are more exclusive, we expect that satisfaction, investments, and alternatives are more important for friendship commitment and stability among girls than among boys (Oswald et al., 2004). The role of alternatives may differ in particular between girls and boys because girls may be inclined to terminate a friendship when they have a better alternative, but boys may keep their old friend and simply extend their friendship network.

Age differences may also influence investment model processes. From late childhood to middle adolescence, emphasis on sharing activities with friends declines and concern with shared secrets, worries, ambitions, and trust become more important (Berndt \& Perry, 1986). Also, emphasis on individuality increases while controlling the relationship and conformity both decline over the course of adolescence (Shulman, Laursen, Kalman, \& Karpovsky, 1997). Satisfaction, companionship, admiration, and reliable alliance also tend to decline (Laursen, 1996). Some studies reported increases in intimacy and affection in friendships over the course of adolescence (Furman \& Buhrmester, 1992). Thus, intimacy and emotional closeness become more important compared to mere companionship, which suggest that investments, satisfaction, and quality of alternatives are more important in middle adolescence than in early adolescence.

\section{Overview}

This study is the first to longitudinally investigate the applicability of the investment model to adolescents' same-sex best friendships. It contributes to the existing literature by examining commitment processes in the developmental period of adolescence in both early and 
middle adolescents. Furthermore, it investigates the investment model's power in predicting stability of best friendships in two ways.

To test our predictions, we conducted a two-wave prospective study on adolescent best friendships among a large sample of early and middle adolescents. Using confirmatory factor analysis, we examine whether we can identify the different elements of the investment model in adolescents' friendships. Additionally, we examine to what extent satisfaction, alternatives, and investments adequately predict commitment in friendships relationships, both concurrently and over time. Furthermore, we examine to what extent commitment predicts friendship stability in adolescence. We measure friendship stability dichotomously not only by comparing the name of the best friend nominated by the adolescents over the course of the study but also on a continuous scale by asking the adolescents to report their tendency to switch friends. This allows us to examine longitudinally the extent to which an adolescent is (thinking about) looking for another best friend in stable best friendships. We hypothesize that satisfaction, investments, alternatives, and commitment will predict friendship stability and that commitment plays a mediational role in the prediction of satisfaction, alternatives, and investments with future commitment and stability. We also expect that the role of good alternatives in the prediction of commitment and stability in adolescent friendships may be less pronounced than for romantic relationships. Finally, we examine differences in these relations between boys and girls and between early and middle adolescents. We hypothesize that investments, satisfaction, and quality of alternatives are more important for commitment and stability for girls than for boys and more important in middle adolescence than in early adolescence.

\section{Method}

\section{Participants}

Data of this study come from the first and second wave of the CONAMORE 20012006 longitudinal study conducted in The
Netherlands (CONflict And Management Of Relationships; Meeus et al., 2004). We followed a total of 1,324 adolescent children longitudinally with a 1-year interval. We excluded from the study 34 adolescents who reported not having a best friend at Time 1 and 56 adolescents who had cross-sex friendships. To deal with interdependent dyads, for 360 mutual friends that both participated in the study, we randomly selected one target per dyad and omitted the other dyad member from the data file. Also, we made sure that all friends were unique and each friend was rated by only one adolescent by randomly selecting one of the targets when they nominated the same friend. This resulted in a sample of 995 adolescents. We estimated missing values in Amos using full information maximum likelihood. The remaining sample of 995 adolescents (533 girls, 462 boys) consisted of 678 early adolescents ( $M$ age $=12.4$ years $)$ and 317 middle adolescents $(M$ age $=16.7$ years $)$. The vast majority $(85.5 \%)$ of the adolescents was of Dutch origin; the others came from Dutch ethnic minorities, with $6 \%$ identifying themselves as Moroccan, 3.5\% as Turkish, 2\% as Surinam/Dutch Antillean, and 3\% as belonging to other non-Western ethnic groups. Our percentage of ethnic minorities closely reflects that of the general Dutch population. Adolescents came from 12 schools in Utrecht and surrounding areas that were representative of the different educational levels in The Netherlands. Adolescents represented different educational levels, with approximately one third of the adolescents being in schools preparing for blue-collar work, one third of the adolescents in schools preparing for higher professional education, and one third of the adolescents in schools preparing for university. (Because classes are often combinations of different school levels, exact numbers cannot be provided).

\section{Procedure}

Before the start of the study, students and their parents received written information and, if the student agreed to participate, provided written informed consent; less than $1 \%$ refused to participate. We also obtained written 
informed consent from principals at all the participating schools. In each wave, interviewers visited schools and asked participating adolescents to fill out a battery of questionnaires after school hours. During school visits, the interviewer started with an explanation of the project and instructions about filling out the questionnaire. We explicitly guaranteed confidentiality. The interviewer asked the adolescents to fill out the questionnaires individually. The presence of the interviewer encouraged complete responding and prevented collaboration among the adolescents as they completed the questionnaire. In both waves, respondents received $€ 10$ (approximately US\$13) after completing the questionnaires.

\section{Measures}

Participants completed a large battery of questionnaires including measures on relationship satisfaction, quality of alternatives, investment level, relationship commitment, and tendency to switch friends. Only those measures relevant to the current study are described.

Investment model scale. A Dutch adaptation of the Investment Model Scale, an instrument designed to measure commitment level, satisfaction level, investment size, and quality of alternatives that has good reliability and validity (for a list of items see Rusbult et al., 1998), assessed investment model variables. Satisfaction assesses the extent to which participants are satisfied with their relationship or experience positive and negative affect in their relationship. We assessed this scale with four items. An item example is: "I am satisfied with the relationship with my friend." Investment size refers to the number, magnitude, and importance of resources that are put into a particular relationship that cannot be retrieved if the relationship ends and was assessed with five items. An example item is: "I lose a lot if the relationship with my friend gets worse." Quality of alternatives assesses the rewards and costs that are expected in the alternatives participants have for the relationship, or the perceived desirability of the best available alternative for the relationship, and was assessed with five items. For example: "I have many opportunities to do things with others than my friend." Commitment level refers to the intent to maintain a relationship and to feel attached to it and was assessed with four items. For example: "I wish the relationship with my friend were to stay the way it is." Respondents answered all items on 5-point Likert scales. Reliability coefficients (Cronbach's alphas) for the investment model variables and commitment in adolescents' friendships in Wave 1 and Wave 2 were .88 and .87 for satisfaction, .81 and .78 for investments, .76 and .71 for alternatives, and .89 and .87 for commitment.

Relationship stability. We assessed relationship stability in two ways. First, we distinguished stable friendships from nonstable friendships by comparing the best friend listed in Wave 1 with the best friend listed in Wave 2. Adolescents who named the same best friend in both waves formed the stable friendship group $(n=419)$, and adolescents who named different friends in the two waves formed the nonstable friendship group $(n=576)$.

Second, we used the reconsideration of commitment subscale of the Utrecht-Management of Identity Commitments Scale (Crochetti \& Meeus, in press; Meeus, 1996) to measure adolescents' tendency to switch best friends. We assessed tendency to switch friends by three items on a 5-point Likert scale ranging from $1=i$ is completely true for me to $5=i$ s not true for me at all. The scale for tendency to switch friends measures the extent to which the adolescent is inclined to look for another best friend. Examples of items are: "I often think about looking for another best friend"; "I often think that another best friend could make my life more interesting"; "I am looking for a different best friend." Cronbach's alphas of this scale were .92 in Wave 1 and .90 in Wave 2.

\section{Results}

\section{Descriptive analyses}

To assess mean differences in investments, quality of alternatives, satisfaction, commitment, and tendency to switch friends between 
Time 1 and Time 2, boys and girls, early and middle adolescents, and stable and nonstable friendships, we performed a series of $2 \times 2 \times 2$ $\times 2$ (Time $\times$ Sex $\times$ Age $\times$ Stability) repeated measures multivariate analysis of variance (MANOVA) with time as within-subject factor and sex, age, and stability as betweengroups factors (see Table 1). Paralleling research on romantic relationships (e.g., for a review, see Le \& Agnew, 2003) results for friendship stability indicated that adolescents in stable friendships were more satisfied, invested more, had a higher commitment, and had a lower tendency to switch friends than adolescents who had a different best friend. We found consistent sex differences, with girls reporting higher levels of satisfaction and commitment, higher investment size, and lower quality of alternatives, and tendency to switch friends than boys. Early adolescents reported lower quality of alternatives than middle adolescents. Satisfaction and commitment increased from Time 1 to Time 2 and tendency to switch friends decreased from Time 1 to Time 2, although interaction effects showed that stability and age qualified the effects for satisfaction and tendency to switch friends. We found a significant interaction between time and age for tendency to switch friends: only middle adolescents decreased in tendency to switch friends $\left(M_{\mathrm{t} \text { early }}=4.12\right.$, $\left.M_{\text {t2early }}=4.09\right)\left(M_{\text {t1 middle }}=4.07, M_{\text {t2middle }}\right.$ $=4.33)$. We found a significant interaction between time and stability for satisfaction and quality of alternatives. The interaction between time and stability for satisfaction revealed that adolescents with stable friendships had the same higher level of satisfaction at Time 1 and Time $2(M=3.84)$, and only adolescents with nonstable friendships increased to a similar level as adolescents with stable friendships $\left(M_{\mathrm{t} 1}=3.65, M_{\mathrm{t} 2}=3.81\right)$. The interaction between time and stability for quality of alternatives revealed that only adolescents with stable friendships tended to have more alternatives at Time $2\left(M_{\mathrm{t} 1 \text { stable }}=\right.$ 2.92, $M_{\text {t2stable }}=3.00, M_{\text {t1 nonstable }}=2.99$, $M_{\text {t2nonstable }}=2.96$ ). We found a significant interaction between stability and sex for quality of alternatives: The difference between boys and girls, with boys having more alter- natives than girls, was greater for adolescents with stable friendships than for adolescents with nonstable friendships $\left(M_{\text {stable boys }}=\right.$ $3.13, M_{\text {stable girls }}=2.79, M_{\text {nonstable boys }}=$ $3.08, M_{\text {nonstable girls }}=2.87$ ). All other interaction terms were not significant.

Crosstabs revealed that girls and boys were equally likely to switch friends, $\chi^{2}(1)=3.33$, $p>.05$. Sixty-one percent of the boys and $55 \%$ of the girls had nonstable friendships. Also, early and middle adolescents were equally likely to switch friends, $\chi^{2}(1)=1.07$, $p>.05$. Fifty-nine percent of the early adolescents and $56 \%$ of the middle adolescents had nonstable friendships.

\section{Relations between investment model variables}

Table 2 presents correlations between all variables. For the remaining analyses, we used structural equation modeling Amos 5.1; Arbuckle, 2003). We performed a confirmatory factor analysis (CFA) on the investment model variables in the first measurement wave with the items of each scale loading on the corresponding factor and correlations between the latent factors (see Figure 1 for the latent part of this model). We allowed correlations between factors. We evaluated model fit by the comparative fit index and the nonnormed fit index, with values above .90 indicating acceptable fit and values above .95 indicating good fit, and the root mean square of error of approximation, with values up to .06 representing a close fit of the model and values up to .10 representing reasonable errors of approximation in the population (Browne \& Cudeck, 1989, 1993; Hu \& Bentler, 1999).

The fit of this model was acceptable (see Table 3). Standardized factor loadings for the investment model variables and commitment for adolescents' relationships with best friends varied from .72 to .88 for satisfaction, from .43 to .77 for investments, from .54 to .65 for alternatives, and from .71 to .95 for commitment. These results show that we can meaningfully assess relationship satisfaction, quality of alternatives, investments, and relationship commitment in adolescents' friendships. 


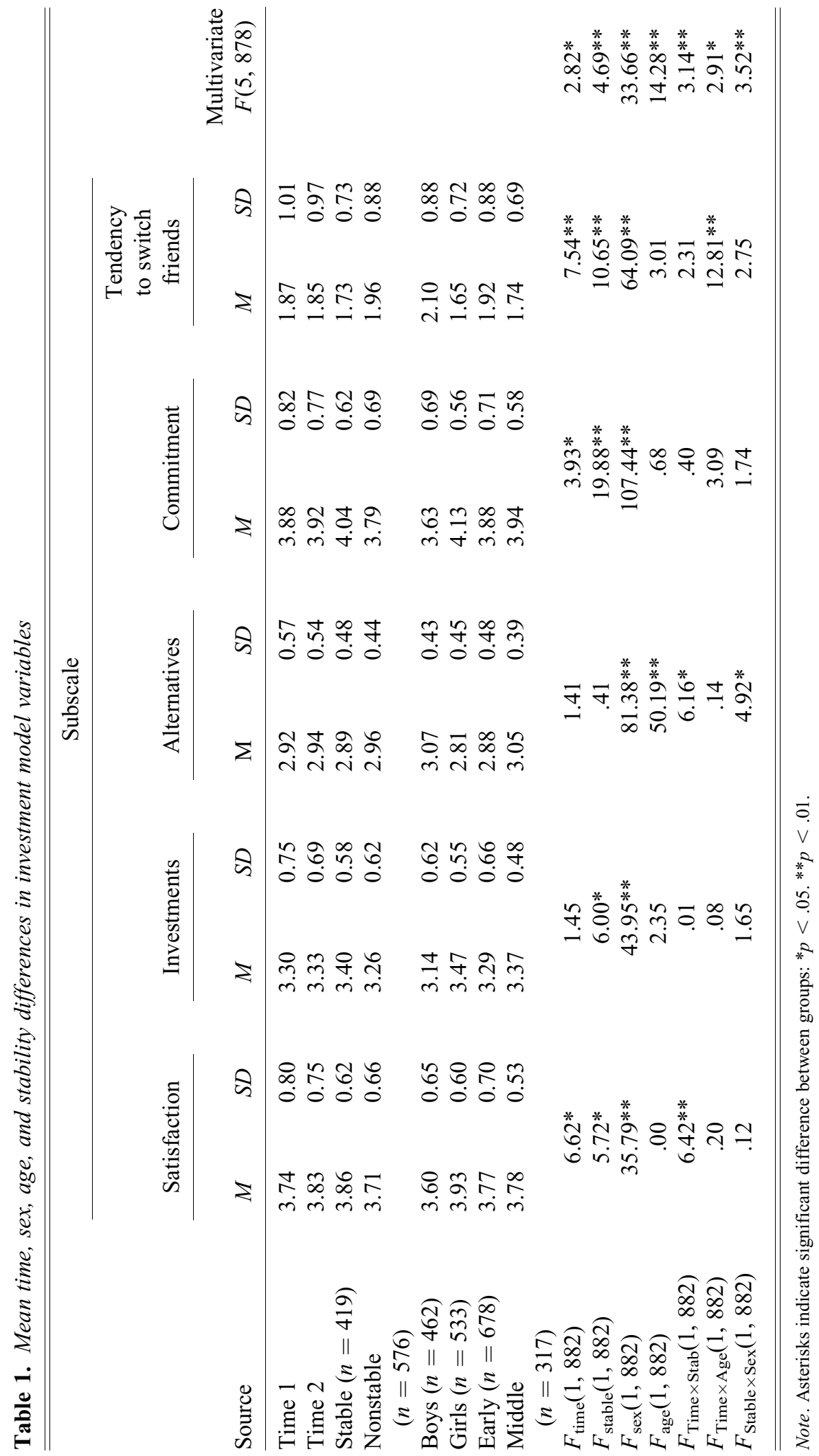




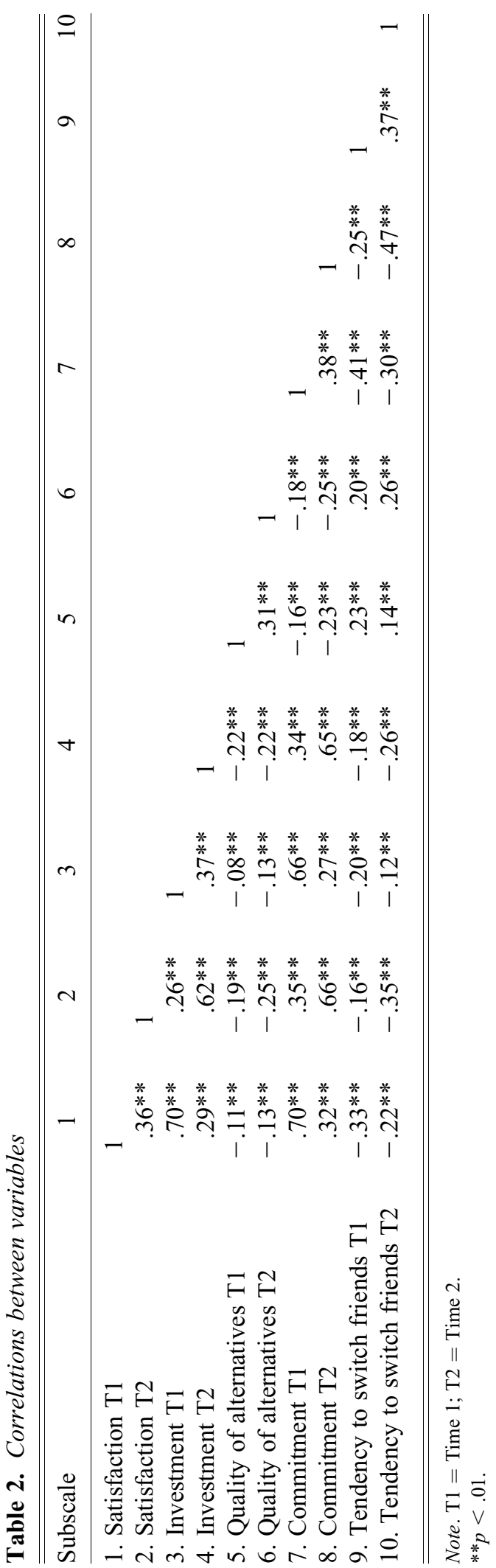


Table 3. Fit indices for investment model and longitudinal prediction of commitment and stability

\begin{tabular}{lcccccc}
\hline \hline Model & $\chi^{2}$ & $\mathrm{df}$ & $\Delta \chi^{2} / \Delta \mathrm{df}$ & NNFI & CFI & RMSEA \\
\hline Four-factor CFA model & $597.89^{* *}$ & 106 & & .90 & .94 & .07 \\
Stable/nonstable equal & $850.90^{* *}$ & 254 & & .90 & .93 & .05 \\
Stable/nonstable different & $831.12^{* *}$ & 248 & $19.78 / 6^{* *}$ & .90 & .93 & .05 \\
Prediction of friendship stability & $621.79^{* *}$ & 120 & & .90 & .94 & .07 \\
Prediction of commitment & & & & & & \\
Total & $427.05^{* *}$ & 174 & & .91 & .94 & .06 \\
$\quad$ Multigroup sex equal & $866.71^{* *}$ & 433 & & .87 & .89 & .05 \\
$\quad$ Multigroup sex different & $839.04^{* *}$ & 423 & $27.68 / 10^{*}$ & .87 & .89 & .05 \\
$\quad$ Multigroup age equal & $920.11^{* *}$ & 433 & & .86 & .88 & .05 \\
$\quad$ Multigroup age different & $879.61^{* *}$ & 423 & $40.51 / 10^{* *}$ & .87 & .89 & .05 \\
Prediction of tendency to switch & & & & & & \\
$\quad$ No mediation & $849.29^{* *}$ & 214 & & .83 & .88 & .08 \\
$\quad$ Full mediation & $488.90^{* *}$ & 214 & & .93 & .95 & .06 \\
$\quad$ Partial mediation & $485.55^{* *}$ & 211 & $3.35 / 3$ & .93 & .95 & .06 \\
Full mediation age equal & $948.94^{* *}$ & 496 & & .90 & .92 & .05 \\
$\quad$ Full mediation age different & $912.90^{* *}$ & 484 & $36.04 / 12^{* *}$ & .90 & .92 & .05 \\
$\quad$ Full mediation sex equal & $862.28^{* *}$ & 496 & & .91 & .93 & .04 \\
Full mediation sex different & $810.29^{* *}$ & 484 & $51.99 / 12^{* *}$ & .92 & .94 & .04 \\
\hline \hline
\end{tabular}

Note. CFA = confirmatory factor analysis; $\mathrm{NNFI}=$ non-normed fit index $\mathrm{CFI}=$ comparative fit index; RMSEA $=$ root mean square error of approximation.

$* p<.05 . * * p<.01$.

In this CFA, we estimated correlations between relationship satisfaction, quality of alternatives, investments, and relationship commitment. In a multigroup model, we next estimated these relationships for adolescents with stable and nonstable friendships separately. A chi-square difference test revealed that the model with different correlations for stable and nonstable friendships provided a better fit to the data than the model with equality constraints across groups (Table 3, fourth row, fourth column). Results are displayed in Table 4. Generally, the correlations indicate that commitment, investments, and satisfaction are strongly related in the expected directions, although the relations of invest-

Table 4. Concurrent latent associations between Time 1 investment model variables in best friendships

\begin{tabular}{lccc}
\hline \hline Correlation & Total & Stable friendships & Nonstable friendships \\
\hline Commitment $\leftrightarrow$ Alternatives & -.01 & $-.12_{\mathrm{a}}^{*}$ & $.07_{\mathrm{b}}$ \\
Commitment $\leftrightarrow$ Satisfaction & $.75^{* *}$ & $.79_{\mathrm{b}}{ }^{* *}$ & $.72_{\mathrm{a}}^{* *}$ \\
Investments $\leftrightarrow$ Commitment & $.79^{* *}$ & $.84_{\mathrm{b}}{ }^{* *}$ & $.76_{\mathrm{a}}^{* *}$ \\
Investments $\leftrightarrow$ Alternatives & $.09^{*}$ & $-.06_{\mathrm{a}}$ & $.17_{\mathrm{b}}{ }^{* *}$ \\
Investments $\leftrightarrow$ Satisfaction & $.83^{* *}$ & $.81^{* *}$ & $.83^{* *}$ \\
Alternatives $\leftrightarrow$ Satisfaction & .05 & $-.08_{\mathrm{a}}$ & $.15_{\mathrm{b}}{ }^{* *}$ \\
\hline \hline
\end{tabular}

Note. Different subscript letters indicate differences between groups at $p<.05$. ${ }^{*} p<.05 .{ }^{* *} p<.01$. 
ment with commitment and satisfaction were stronger than expected. The relations of commitment to satisfaction and investments were stronger for adolescents with stable friendships. Although quality of alternatives was significantly correlated with investments in the total sample, with higher quality of alternatives being related to more investments, it was differentially related to investments, satisfaction, and commitment in the stable versus nonstable friendship groups (Table 4). Among adolescents in a stable friendship, having highquality alternatives was associated with less commitment. In contrast, among adolescents in nonstable friendships, having high-quality alternatives was associated with more investments and higher satisfaction.

\section{Predicting friendship stability from the investment model variables}

To examine whether the investment model variables could predict which adolescents would have stable friendships and which adolescents would have a different best friend 1 year later, we estimated effects of Wave 1 relationship satisfaction, quality of alternatives, investments, and relationship commitment on the dichotomous variable friendship stability (for the fit of this model see Table 3). Results showed a significant effect of quality of alternatives $(\beta=-.13, p<.01)$. Satisfaction, investments, and relational commitment did not predict friendship stability $\left(\beta_{\text {satisfaction }}\right.$ $=.12, \beta_{\text {investments }}=-.04, \beta_{\text {commitment }}=.09$, $p>.05)$. Thus, adolescents with fewer alternatives were more likely to have the same best friend 1 year later.

\section{Longitudinal prediction of commitment in stable best friendships}

For the longitudinal analyses, we only used adolescents with stable friendships who reported on the same best friend in both waves. For those adolescents who had stable friendships $(n=419)$, we estimated effects of Wave 1 relationship satisfaction, quality of alternatives, investments, and relationship commitment on Wave 2 relationship commitment. Figure 2 shows the latent model as estimated

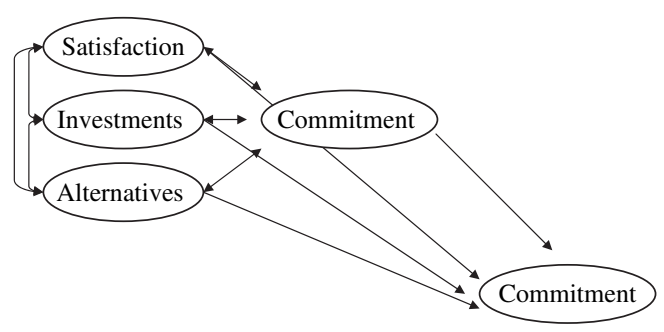

Figure 2. Longitudinal associations between satisfaction level, investment size, quality of alternatives, and commitment level.

for adolescents' relationships with their friend. We set loadings and correlated errors within each factor equal across the two waves. Table 3 displays the fit indices for the model, which indicate that the fit was adequate. Table 5 (2nd column) displays the correlations and path coefficients between the investment model variables and commitment for adolescents in stable friendships. Again, the correlations indicate that commitment, investments, and satisfaction are strongly related. Moreover, for these adolescents with stable friendships, quality of alternatives was negatively correlated to commitment. Further, commitment appeared not to be very stable over time. Additionally, quality of alternatives predicted commitment over time, indicating that adolescents with lower quality of alternatives for their friendship were more committed to their best friend 1 year later.

To examine the moderating effects of sex and age on these relations, we repeated the analyses in two additional multigroup analyses in which we distinguished boys versus girls and early versus middle adolescents, respectively, as the two groups. We compared models in which we set correlations and paths for boys and girls or early and middle adolescents equal to models in which we allowed correlations and paths for sex or age to differ. We specified measurement invariance across groups. Chisquare difference tests revealed that the models with different correlations and paths for sex and age provided a better fit to the data than the models with equality constraints (Table 3 ). Results of these models are displayed in Table 5. Some striking differences appeared 
Table 5. Standardized parameter estimates for model of longitudinal prediction of commitment

\begin{tabular}{|c|c|c|c|c|c|}
\hline Association & Total & Early & Middle & Boys & Girls \\
\hline \multicolumn{6}{|l|}{ T1 latent } \\
\hline \multicolumn{6}{|l|}{ concurrent associations } \\
\hline Commitment $\leftrightarrow$ Alternatives & $-.14 *$ & $-.06_{\mathrm{a}}$ & $-.61_{\mathrm{b}} * *$ & $-.07 \mathrm{a}$ & $-.29_{b}^{* *}$ \\
\hline Commitment $\leftrightarrow$ Satisfaction & $.76^{* *}$ & $.72 * *$ & $.70 * *$ & $.66 * *$ & $.78 * *$ \\
\hline Investments $\leftrightarrow$ Commitment & $.81 * *$ & $.73_{\mathrm{a}} * *$ & $.86_{\mathrm{b}} * *$ & $.73 * *$ & $.79 * *$ \\
\hline Investments $\leftrightarrow$ Alternatives & -.05 & $.05_{\mathrm{a}}$ & $-.74 \mathrm{~b} * *$ & $.17_{\mathrm{a}}$ & $-.19_{b} *$ \\
\hline Investments $\leftrightarrow$ Satisfaction & $.81 * *$ & $.79^{* *}$ & $.83 * *$ & $.76^{* *}$ & $.78 * *$ \\
\hline Alternatives $\leftrightarrow$ Satisfaction & -.10 & $-.01_{\mathrm{a}}$ & $-.66_{\mathrm{b}} * *$ & $.12_{\mathrm{a}}$ & $-.27_{\mathrm{b}}^{* *}$ \\
\hline \multicolumn{6}{|l|}{ Longitudinal associations } \\
\hline Commitment $\rightarrow$ Commitment $\mathrm{T} 2$ & $.23 *$ & .16 & .29 & $.30_{\mathrm{a}}^{*}$ & $.06_{\mathrm{b}}$ \\
\hline Satisfaction $\rightarrow$ Commitment T2 & -.01 & -.03 & .09 & -.13 & .17 \\
\hline Alternatives $\rightarrow$ Commitment $\mathrm{T} 2$ & $-.30 * *$ & $-.28 * *$ & -.22 & $-.34_{\mathrm{a}} * *$ & $-.14_{b}$ \\
\hline Investments $\rightarrow$ Commitment $\mathrm{T} 2$ & .20 & .22 & .03 & $.15^{a}$ & .16 \\
\hline
\end{tabular}

Note. Different subscript letters indicate differences between groups at $p<.05$. T1 $=$ Time $1 ;$ T2 $=$ Time 2 . $* p<.05 . * *<.01$.

regarding quality of alternatives: quality of alternatives was significantly and negatively related to commitment, satisfaction, and investments for middle adolescents but not for early adolescents. Also, investment size was more strongly related to commitment for middle adolescents than for early adolescents. Critical ratios indicated that coefficients were significantly different for early and middle adolescents. Comparably, the correlation of alternatives with satisfaction, commitment, and investments was significant for girls only, and this coefficient was significantly stronger than the coefficient for boys. These findings suggest that the investment model is better able to explain processes in girls' than boys' friendships and in middle than early adolescents' friendships.

Over time, differences between groups were less consistent. The only significant difference was that, in addition to commitment in Wave 1, fewer quality of alternatives predicted commitment for boys and not for girls. Some other effects were significant for one of the groups only, but in these cases coefficients did not differ significantly between the two groups. Some effects for boys and girls and early and middle adolescents significantly differed, but these differences did not concern significant effects and we therefore do not describe these differences in detail.

\section{Longitudinal prediction of tendency to switch friends in stable best friendships}

Next, we examined the effects of satisfaction, investments, quality of alternatives, and commitment on the tendency to switch friends. We assessed the effects of satisfaction, investments, alternatives, and commitment on Wave 2 tendency to switch friends while controlling for the relations between the Wave 1 variables and the stability of tendency to switch friends (see Figure 3). To examine whether commitment mediated the effect of satisfaction, alternatives, and investments on tendency to switch friends, we estimated and compared three models: (a) no mediation model with

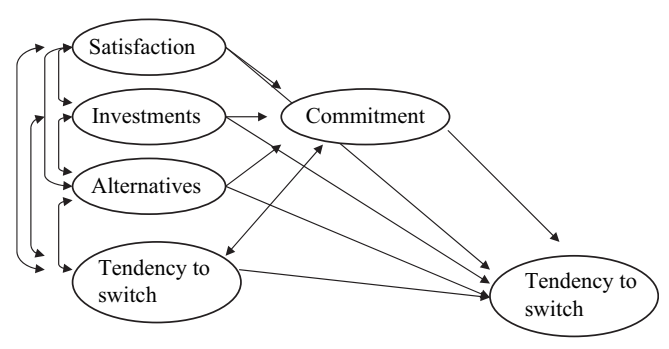

Figure 3. Longitudinal associations between satisfaction level, investment size, quality of alternatives, commitment level, and tendency to switch best friends. 
direct effects of satisfaction, alternatives, and investments on tendency to switch friends and no mediation of commitment (i.e., without paths from investment, satisfaction, and alternatives to commitment); (b) a full mediation model in which commitment fully mediated the effects of satisfaction, alternatives, and investments on tendency to switch friends (i.e., with no direct effects of satisfaction, alternatives, and investments on tendency to switch friends); and (c) a partial mediation model in which we allowed both direct and indirect effects of satisfaction, alternatives, and investments on tendency to switch friends (i.e., with all paths displayed in Figure 3; Kim, Kaye, \& Wright, 2001; MacKinnon, Lockwood, Hoffman, West, \& Sheets, 2002). Fit indices of these models are displayed in Table 3.

A chi-square comparison test revealed that the model with full mediation by commitment fitted better than the no mediation model and did not fit significantly worse than the partially mediated model. Because the full mediation model is a restricted version of the partial mediation model, the full mediation model is more preferable than the partial mediation model. Results of the fully mediated model indicated that satisfaction, investments, and commitment were moderately negatively related to tendency to switch friends, and quality of alternatives was positively related to tendency to switch friends, suggesting that adolescents with lower satisfaction, investments, and commitment and higher quality of alternatives were less likely to switch friends (see Table 6). The longitudinal stability of tendency to switch friends was moderate, and a higher Wave 1 commitment to best friend predicted lower Wave 2 tendency to switch friends.

We also estimated the fully mediated model in two multigroup analyses in which we distinguished sex and age as the two groups. We compared models in which we set equal the correlations and paths for boys and girls or early and middle adolescents to models in which we allowed correlations and paths for sex or age to differ (see Table 3). Again, we specified measurement invariance across groups. Chi-square difference tests revealed that the models with different correlations

Table 6. Standardized parameter estimates for model of longitudinal prediction of tendency to switch friends

\begin{tabular}{lccccc}
\hline \hline Association & Total & Early & Middle & Boys & Girls \\
\hline T1 concurrent associations & & & & & \\
Satisfaction $\leftrightarrow$ Alternatives & $-.14^{*}$ & $-.05_{\mathrm{a}}$ & $-.56_{\mathrm{b}} * *$ & $.12_{\mathrm{a}}$ & $-.30_{\mathrm{b}} * *$ \\
Investments $\leftrightarrow$ Satisfaction & $.81^{* *}$ & $.82^{* *}$ & $.79^{* *}$ & $.87^{* *}$ & $.80^{* *}$ \\
Investments $\leftrightarrow$ Alternatives & -.09 & $.01_{\mathrm{a}}$ & $-.61_{\mathrm{b}} * *$ & $.18_{\mathrm{a}}$ & $-.23_{\mathrm{b}} * *$ \\
Satisfaction $\leftrightarrow$ Switch friends & $-.42^{* *}$ & $-.40^{* *}$ & $-.50^{* *}$ & $-.23_{\mathrm{a}}^{* *}$ & $-.56_{\mathrm{b}}^{* *}$ \\
Investments $\leftrightarrow$ Switch friends & $-.33^{* *}$ & $-.29_{\mathrm{a}}^{* *}$ & $-.50_{\mathrm{b}}^{* *}$ & $-.12_{\mathrm{a}}$ & $-.48_{\mathrm{b}}^{* *}$ \\
Commitment $\leftrightarrow$ Switch friends & $-.23^{* *}$ & $-.19^{*}$ & $-.20^{*}$ & -.31 & $-.31^{* *}$ \\
Alternatives $\leftrightarrow$ Switch friends & $.39^{* *}$ & $.36_{\mathrm{a}}^{* *}$ & $.56_{\mathrm{b}}^{* *}$ & $.32^{* *}$ & $.37^{* *}$ \\
Alternatives $\rightarrow$ Commitment & $-.10^{* *}$ & $-.09^{*}$ & -.14 & -.11 & $-.14^{*}$ \\
Satisfaction $\rightarrow$ Commitment & $.37^{* *}$ & $.54_{\mathrm{b}}^{* *}$ & $.17_{\mathrm{a}}$ & -.03 & $.35^{* *}$ \\
Investments $\rightarrow$ Commitment & $.54^{* *}$ & $.40^{* *}$ & $.64^{* *}$ & $.97_{\mathrm{b}}^{* *}$ & $.54_{\mathrm{a}}^{* *}$ \\
Longitudinal associations & & & & & $.22^{* *}$ \\
Switch friends T1 $\rightarrow$ T2 & $.23^{* *}$ & $.15^{*}$ & $.30^{* *}$ & $.17^{*}$ & .10 \\
Commitment $\rightarrow$ Switch & $-.22^{* *}$ & $-.20^{* *}$ & -.19 & $-.23^{* *}$ & -.10 \\
friends T2 & & & & & \\
\hline \hline
\end{tabular}

Note. Different subscript letters indicate differences between groups at $p<.05$. T1 $=$ Time $1 ; \mathrm{T} 2=$ Time 2 . ${ }^{*} p<.05 . * * p .01$. 
and paths for sex and age provided a better fit to the data than the models with equality constraints. Parameter estimates of these models are displayed in Table 6 .

Critical ratio comparisons revealed a few significant differences between girls and boys and between early and middle adolescents. Satisfaction and investments were more strongly related to tendency to switch friends among girls than among boys. Quality of alternatives and investments were more strongly related to the tendency to switch friends among middle adolescents than among early adolescents. In other words, girls were less likely than boys to consider switching friends when they were more satisfied and when they invested more in their relationship with their best friend, and middle adolescents were more likely than early adolescents to consider switching friends when better alternatives were available and when they had invested less. Again, these findings suggest that the investment model more accurately describes processes in girls' than boys' friendships and in middle than early adolescents' friendships. The investment model thus seems better able to explain relationship processes in more exclusive relationships.

\section{Discussion}

The goal of the present study was to investigate longitudinally the applicability of the investment model to adolescents' best friendships and to assess its predictive power regarding friendship stability. We examined differences between the best friendships of early versus middle adolescents and of boys versus girls in the interrelations among investment model concepts. Results showed that the investment model is meaningfully applicable to adolescents' best friendships and that investment model variables are longitudinally predictive of friendship stability and, among stable friendships, of relational commitment and the tendency to switch friends. Findings further indicated differences in the interrelations among investment model variables between stable and unstable best friendships, as well as age and gender differences.
Results of the CFA revealed that relationship satisfaction, quality of alternatives, investments, and relational commitment could be identified as separate factors in adolescent best friendships. All investment model variables were correlated with each other in the predicted directions, although the concurrent associations among satisfaction, investment, and commitment seemed to be stronger than in studies of romantic partners (e.g., Rusbult, 1983; Rusbult et al., 1986). It is possible that adolescents do not distinguish between these aspects of their friendships as strongly as partners in a romantic relationship do.

Perhaps the most important finding of this study is that the investment model can predict friendship stability. Adolescents whose best friend in the second measurement wave differed from the one in the first measurement wave reported lower levels of satisfaction, investments, and commitment regarding their friendship in the first wave. Moreover, quality of alternatives predicted whether the best friendship would last until the second measurement wave 1 year later. Among adolescents involved in stable friendships, those who reported higher levels of satisfaction, investments, and commitment and lower quality of alternatives in their friendship had a lower tendency to switch friends. Furthermore, higher quality of alternatives was longitudinally predictive of stronger commitment, and higher levels of commitment to the best friend were longitudinally predictive of a lower tendency to switch friends. Thus, friendship commitment is an important predictor of friendship stability.

Quality of alternatives seems to play an important though somewhat complicated role in adolescents' best friendships. It was the only variable that predicted friendship stability. As expected, having higher quality alternatives made adolescents more likely to have a new best friend after 1 year. Among adolescents in a stable best friendship, quality of alternatives was inversely related to satisfaction, investments, and commitment and was a longitudinal predictor of commitment in the expected direction. In contrast, among adolescents whose friendship would prove unstable 1 year later, having higher quality alternatives was 
linked to higher satisfaction and more investments but was not related to commitment.

These differences involving quality of alternatives between stable and nonstable friendships may be due to the nature of friendships in adolescence. Whereas most youngsters have only one romantic or marital partner at the same time (at least in Western cultures), it is common to have multiple friends, and thus having alternative friends does not have to be a threat for the relationship with the best friend. In fact, adolescents may be building a high-quality network of friends by investing in one friendship before moving on to another best friend. They may keep their former best friend and simply extend their friendship network when the switch is made. In line with this suggestion, friendships tend to be less stable when adolescents are highly engaged in the relationship (Way et al., 2001). The fact that, in the current study, higher quality of alternatives was linked with lower satisfaction and less investments only for middle adolescents and girls is also in line with this suggestion. Boys have larger friendship networks and less exclusive relationships than girls (Cairns et al., 1995; Graham et al., 1998), and as they get older, adolescents' relationships become more exclusive (Berndt, 1982; Clark-Lempers, Lempers, \& Ho, 1991). On the other hand, adolescents with low-quality alternatives for their friendship were unlikely to replace their best friend and those that stuck with their best friend were, in turn, more committed to that friend 1 year later. This seems to suggest that while having high-quality alternatives is not threatening to a friendship, having low-quality alternatives is actually conducive to a best friendship. Thus, when best friends are scarce, adolescents work to keep the one they have, but when alternatives are plenty, they extend their friendship network to include new best friends.

Our results provide some support for the assumption of the investment model that relational commitment mediates the effects of satisfaction, investment, and quality of alternatives on the course of a relationship. That is, in the longitudinal prediction of the tendency to switch friends, a full mediation model provided the best fit. Thus, commitment mediated the effect of the other investment model variables on tendency to switch friends. Findings concerning the proposed mediational role of commitment are mixed, and many studies do not support it (e.g., Bui et al., 1996; Sacher \& Fine, 1996). In the current study, the mediation was found among adolescents in stable friendships. These adolescents were highly committed to their best friend and, given the fact that their friendship was stable, probably not much inclined to look for another best friend. Further research is needed to examine whether commitment mediates the effects of the other investment model variables on tendency to switch in adolescents that are less committed to their friends. This would be especially important in light of the unexpected but remarkable finding that commitment in adolescents' friendships was not very stable over time. Stability of commitment was highest among middle adolescents and among boys. These results are difficult to explain and in need of replication in future studies.

On the whole, in line with our expectations, the investment model seemed more suited to explaining middle adolescents' best friendships than early adolescents' best friendships. Quality of alternatives was negatively related to commitment, satisfaction and investments for middle adolescents, but not for early adolescents, and the association of quality of alternatives with tendency to switch friends was stronger for middle adolescents than for early adolescents. These findings may indicate that as adolescents get older, their friendships become more exclusive and develop toward greater intimacy (Berndt, 1982; Clark-Lempers et al., 1991). As their best friendship becomes more exclusive, the quality of alternatives becomes more important.

Overall, the results of the present study indicate quite clearly that relations between investment model variables were stronger for girls than for boys, thereby confirming our hypotheses. Quality of alternatives was significantly related to commitment, satisfaction, and investments for girls only. These findings are in line with the idea that females are socialized to place more importance on the formation and maintenance of relationships (Camarena, Sarigiani, \& Petersen, 1990). Adolescent girls 
focus on the emotional aspects of relationships more and report higher levels of emotional closeness, commitment, and intimacy in their relationships than do boys (Berndt, 1982; Clark-Lempers et al., 1991; Furman \& Buhrmester, 1992; Johnson, 2004; Lempers \& Clark-Lempers, 1993). Girls expect more conventional morality, loyalty and commitment, and empathic understanding from their friends than boys, and girls more often than boys report having friendships characterized by higher levels of conventional morality, loyalty and commitment, and empathic understanding (Clark \& Bittle, 1992). Of course, future research is needed to replicate these findings.

On the whole, our results are in line with the idea that the investment model works best for exclusive dyadic relationships (Lin \& Rusbult, 1995). First, the investment model worked better for girls than for boys, and girls are thought to have more exclusive friendships. Second, the investment model worked better for middle adolescents than for early adolescents, and middle adolescents are thought to have more intimate and exclusive friendships than early adolescents. It should be noted that the current study investigated only same-sex best friendships. Although a small number of adolescents reported a cross-sex best friendship, there were too few to include them in our analyses, and our study thus reflects the fact that early and middle adolescents' best friendships are predominantly same-sex friendships. As they get older, adolescents increasingly engage in cross-sex friendships. It would be interesting to examine commitment processes in cross-sex friendships and compare these friendships with same-sex friendships and romantic relationships.

An important strength of this study is the longitudinal design that allowed for the inclusion of both stable and nonstable friendships. On the one hand, this allowed us to examine the investment model's potency in predicting relationship stability prospectively. On the other hand, it allowed us to compare investment model processes in relationships that would prove stable versus nonstable 1 year later. Clear limitations of our study are that only one partner in a best friendship filled out the questionnaire and we had self-reports of friendship only. Common method variance, or the tendency of respondents to answer different questions in the same way, may have inflated the links between the investment model variables. Nonetheless, we found that the associations between the investment model variables are different for early versus middle adolescents and for boys versus girls, and it is unlikely that common method variance has a differential effect across different groups.

An additional limitation is that adolescents might have nominated different best friends at the two time points for various reasons. Although some adolescents might nominate a real new best friend, others might just nominate different "best" friends at the two time points, and others might nominate a different friend for reasons outside their direct control (e.g., because the old friend has moved). Nevertheless, we included an additional measure of friendship stability that reflects the attitude of the adolescent toward switching best friends, and the investment model was also predictive of this measure of friendship stability.

Furthermore, our results are limited to a normal population of Dutch adolescents. Although we do not expect friendships of Dutch adolescents to differ from adolescents' friendships in other Western cultures, future research should replicate these findings in other countries. Also, future research should examine the generalizability of the findings to non-Western countries. Perhaps in more collectivistic cultures, the role of alternatives is more important than in more individualistic cultures. Also, research in clinical samples needs to examine the role of the investment model in friendships of adolescents with social problems. The findings of these studies might provide cues for intervention.

In conclusion, the investment model has proven to be fruitful in explaining commitment and stability in adolescent best friendships. The investment model can not only predict which friendships will last for at least a year but also subsequently predict the extent to which stable friends are committed to their best friend and the extent to which they are inclined to look for another best friend. 


\section{References}

Acitelli, L. K. (1992). Gender differences in relationship awareness and marital satisfaction among young married couples. Personality and Social Psychology Bulletin, 18, 102-110.

Arbuckle, J. L. (2003). Amos 5.0: Update to the Amos user's guide. Chicago: Smallwaters Corporation.

Berndt, T. J. (1982). The features and effects of friendship in early adolescence. Child Development, 53, 1447-1460.

Berndt, T. J., \& Hoyle, S. G. (1985). Stability and change in childhood and adolescent friendships. Developmental Psychology, 21, 1007-1015.

Berndt, T. J., \& Perry, T. B. (1986). Children's perceptions of friendships as supportive relationships. Developmental Psychology, 22, 640-648.

Brendgen, M., Markiewicz, D., Doyle, A. B., \& Bukowski, W. M. (2001). The relations between friendship quality, ranked-friendship preference, and adolescents' behavior with their friends. Merrill-Palmer Quarterly, 47, 395-415.

Browne, M. W., \& Cudeck, R. (1989). Single sample cross-validation indices for covariance structures. Multivariate Behavioral Research, 24, 445-455.

Browne, M. W., \& Cudeck, R. (1993). Alternative ways of assessing model fit. In K. A. Bollen \& J. S. Long (Eds.), Testing structural equation models (pp. 132162). Beverley Hills, CA: Sage.

Bui, K. T., Peplau, L. A., \& Hill, C. T. (1996). Testing the Rusbult model of relationship commitment and stability in a 15-year study of heterosexual couples. Personality and Social Psychology Bulletin, 22, 1244-1257.

Cairns, R. B., Leung, M. C., Buchanan, L., \& Cairns, B. D. (1995). Friendships and social networks in childhood and adolescence: Fluidity, reliability, and interrelations. Child Development, 66, 1330-1345.

Camarena, P. M., Sarigiani, P. A., \& Petersen, A. C. (1990). Gender-specific pathways to intimacy in early adolescence. Journal of Youth and Adolescence, 19, 19-32.

Carpenter, P. J., \& Coleman, R. (1998). A longitudinal test of elite youth cricketers' commitment. International Journal of Sport Psychology, 29, 195-210.

Clark, M. L., \& Bittle, M. L. (1992). Friendship expectations and the evaluation of present friendships in middle childhood and early adolescence. Child Study Journal, 22, 115-135.

Clark-Lempers, D. S., Lempers, J. D., \& Ho, C. (1991). Early, middle, and late adolescents' perceptions of their relationships with significant others. Journal of Adolescent Research, 6, 296-315.

Connolly, J., Furman, W., \& Konarski, R. (2000). The role of peers in the emergence of heterosexual romantic relationships in adolescence. Child Development, 71, 1395-1408.

Crocetti, E., Rubini, M., \& Meeus, W. (in press). Capturing the dynamics of identity formation in various ethnic groups: Development and validation of a threedimensional model. Journal of Adolescence.

Degirmencioglu, S. M., Urberg, K. A., Tolson, J. M., \& Richard, P. (1998). Adolescent friendship networks: Continuity and change over the school year. MerrillPalmer Quarterly, 44, 313-337.

Feiring, C . (1999). Other-sex friendship networks and the development of romantic relationships in adolescence. Journal of Youth and Adolescence, 28, 495-512.
Floyd, F. J., \& Wasner, G. H. (1994). Social exchange, equity, and commitment: Structural equation modeling of dating relationships. Journal of Family Psychology, $8,55-73$.

Furman, W., \& Buhrmester, D. (1992). Age and sex differences in perceptions of networks of personal relationships. Child Development, 63, 103-115.

Graham, J. A., Cohen, R., Zbikowski, S. M., \& Secrist, M. E. (1998). A longitudinal investigation of race and sex as factors in children's classroom friendship choices. Child Study Journal, 28, 245-266.

Hardy, C. L., Bukowski, W. M., \& Sippola, L. K. (2002). Stability and change in peer relationships during the transition to middle-level school. Journal of Early Adolescence, 22, 117-142.

Hu, L. T., \& Bentler, P. M. (1999). Cut-off criteria for fit indexes in covariance structure analysis: Conventional criteria versus new alternatives. Structural Equation Modeling, 6, 1-55.

Johnson, H. D. (2004). Gender, grade and relationship differences in emotional closeness within adolescent friendships. Adolescence, 39, 243-255.

Kim, J. S., Kaye, J., \& Wright, L. K. (2001). Moderating and mediating effects in causal models. Issues in Mental Health Nursing, 22, 63-75.

Kirkpatrick, L. A., \& Davis, K. E. (1994). Attachment style, gender, and relationship stability: A longitudinal analysis. Journal of Personality and Social Psychology, 66, 502-512.

Laursen, B. (1996). Closeness and conflict in adolescent peer relationships: Interdependence with friends and romantic partners. In W. M. Bukowski, A. F. Newcomb, \& W. W. Hartup (Eds.), The company they keep: Friendship in childhood and adolescence (pp. 186-210). New York: Cambridge University Press.

Laursen, B., \& Bukowski, W. M. (1997). A developmental guide to the organisation of close relationships. International Journal of Behavioral Development, 21, 747-770.

Le, B., \& Agnew, C. R. (2003). Commitment and its theorized determinants: A meta-analysis of the Investment Model. Personal Relationships, 10, 37-57.

Lempers, J. D., \& Clark-Lempers, D. S. (1993). A functional comparison of same-sex and opposite sex friendships during adolescence. Journal of Adolescent Research, 8, 89-108.

Lin, Y. W., \& Rusbult, C. E. (1995). Commitment to dating relationships and cross-sex friendships in America and China. Journal of Social and Personal Relationships, 12, 7-26.

MacKinnon, D. P., Lockwood, C. M., Hoffman, J. M., West, S. G., \& Sheets, V. (2002). A comparison of methods to test mediation and other intervening variable effects. Psychological Methods, 7, 83-104.

Meeus, W. (1996). Studies on identity development in adolescence: An overview of research and some new data. Journal of Youth and Adolescence, 25, 569-598.

Meeus, W., Akse, J., Branje, S. J. T., Ter Bogt, T., Delsing, M., van Doorn, M, et al. (2004). Codeboek van het onderzoeksproject CONflicts and MAnagement of Relationships (CONAMORE). Eerste meetronde: 2001 [Codebook of the research project CONflicts and MAnagement Of Relationships (CONAMORE). First wave: 2001]. Unpublished manuscript, Utrecht University, The Netherlands. 
Neckerman, H. J. (1996). The stability of social groups in childhood and adolescence: The role of the classroom social environment. Social Development, 5, 131-145.

Newcomb, A. F., \& Bagwell, C. L. (1995). Children's friendship relations: A meta-analytic review. Psychological Bulletin, 117, 306-347.

Oswald, D. L., \& Clark, E. M. (2003). Best friends forever?: High school best friendships and the transition to college. Personal Relationships, 10, 187-196.

Oswald, D. L., Clark, E. M., \& Kelly, C. L. (2004). Friendship maintenance behaviors: An analysis of individual and dyad behaviors. Journal of Social and Clinical Psychology, 23, 413-441.

Rusbult, C. E. (1980). Satisfaction and commitment in friendships. Representative Research in Social Psychology, 11, 96-105.

Rusbult, C. E. (1983). A longitudinal test of the investment model: The development (and deterioration) of satisfaction and commitment in heterosexual involvements. Journal of Personality and Social Psychology, 45, 101-117.

Rusbult, C. E., \& Farrell, D. (1983). A longitudinal test of the investment model: The impact on job satisfaction, job commitment, and turnover of variations in rewards, costs, alternatives, and investments. Journal of Applied Psychology, 68, 429-438.

Rusbult, C. E., Johnson, D. J., \& Morrow, G. D. (1986). Predicting satisfaction and commitment in adult romantic involvements: An assessment of the generalizability of the investment model. Social Psychology Quarterly, 49, 81-89.

Rusbult, C. E., Martz, J. M., \& Agnew, C. R. (1998). The Investment Model Scale: Measuring commitment level, satisfaction level, quality of alternatives, and investment size. Personal Relationships, 5, 357-391.

Sacher, J. A., \& Fine, M. A. (1996). Predicting relationship status and satisfaction after six months among dating couples. Journal of Marriage and the Family, $58,21-32$.

Selman, R. L. (1981). The development of interpersonal competence: The role of understanding in conduct. Developmental Review, 1, 401-422.

Shulman, S., Laursen, B., Kalman, Z., \& Karpovsky, S. (1997). Adolescent intimacy revisited. Journal of Youth and Adolescence, 26, 597-617.

Sprecher, S. (1994). Two sides to the breakup of dating relationships. Personal Relationships, 1, 199-222.

Way, N., Cowal, K., Gingold, R., Pahl, K., \& Bissessar, N. (2001). Friendship patterns among African American, Asian American, and Latino adolescents from lowincome families. Journal of Social and Personal Relationships, 18, 29-53.

Worrell, J. (1988). Women's satisfaction in close relationships. Clinical Psychology Review, 8, 477-498. 